\title{
Impact of the integration of tactical supply chain planning determinants on performance
}

\author{
Uche Okongwu $^{\mathrm{a}, *}$, Matthieu Lauras ${ }^{\mathrm{a}, \mathrm{b}}$, Julien François ${ }^{\mathrm{c}}$, Jean-Christophe Deschamps ${ }^{\mathrm{c}}$ \\ a University of Toulouse, Toulouse Business School, Department of Information, Operations and Decision Science, 20 Boulevard Lascrosses, 31000 Toulouse, \\ France \\ ${ }^{\mathrm{b}}$ University of Toulouse, Mines Albi, Department of Industrial Engineering, Route de Teillet, 81013 Albi Cedex 9, France \\ c University of Bordeaux, Department of Production Engineering, IMS-Lab, CNRS 5218, 351 Cours de la Libération, 33405 Talence cedex, France
}

Keywords:

Supply chain management

Performance analysis

Tactical planning

SCOR model

Decoupling point

Simulation

\begin{abstract}
A B S T R A C T
In fulfilling customers' orders, one of the goals of tactical supply chain planning is to satisfy the customers in terms of delivery efficiency, delivery quantity accuracy and on-time delivery. These performance objectives can be impacted by the way firms plan each of the three phases of the supply chain: procurement, production and distribution. Though the link between each of these phases and supply chain performance has been studied in extant literature, very few authors have considered all three phases at the same time. By adopting an integrated approach, this paper therefore aims to study the manner in which, taken together in one model, the planning determinants of the different phases impact on supply chain performance. It is important for managers to understand, from a holistic and integrated perspective, how a given combination of the planning determinants of the supply chain functions impacts positively or negatively on the performance of the supply chain. To carry out this study, this paper starts by proposing an integrated framework that is based on the SCOR model and the customer order decoupling point (CODP), followed by a five-step methodology for tactical supply chain planning. Then, using an analytical model and simulations, and based on a numerical example, it shows how the proposed methodology can be applied in a given decision-making situation. Our results enabled to identify the worst and the best combinations of planning determinants.
\end{abstract}

\section{Introduction}

In the globalised and highly competitive world of today, companies aim to achieve high performance through an effective and efficient management of their supply chains (SC). The Global Supply Chain Forum defined supply chain management (SCM) as "the integration of key business processes from end users through original suppliers who provide products, services, and information that create value for customers and other stakeholders" [1]. This definition allows us to state that the performance of a SC can be leveraged through the effective and efficient design, integration, planning and control of the key business processes. The Supply Chain Operations Reference (SCOR) model provides a processbased framework, which incorporates five main process areas plan, source, make, deliver and return - that constitute a SC [2]. The SCOR model is considered to be a powerful tool that can be used to

\footnotetext{
* Corresponding author. Tel.: +33 561294862; fax: +33 561294994. E-mail address: u.okongwu@tbs-education.fr (U. Okongwu).
}

study and understand how performance variables inter-relate and how to manage the trade-offs resulting from these relationships [3]. Apart from the return process area (which is an aftermarket process), the determinants of each of these process areas (or functions) can impact on the performance of the SC. The source, make and deliver process areas correspond respectively to the procurement, production and distribution functions. Ref. [4] studied and confirmed a positive relationship between supply chain performance and each of the five process areas, but did not investigate the individual or combined impact (on performance) of the determinants of these process areas.

Many researchers have studied the relationship between the determinants of three of these process areas (source, make and deliver) and supply chain performance [5,6]. But, despite the fact that academics and professionals have always thought that significant capacity adjustment expenditures and storage costs might be avoided by better planning [7], the impact of the planning process on performance has not been sufficiently explored [8]. The few studies that have been done on this topic are generally limited only to the manufacturing or production function $[9,10]$. Moreover, most 
of the studies are based on one-to-one or one-to-few relationships. In other words, the authors study the impact of just one or two planning determinants on a few (or a single) performance measures. For example, Ref. [11] looked at the impact of lot sizing and sequencing on manufacturing performance; Refs. $[12,13]$ studied the effect of capacity and sequencing rules; Ref. [14] studied capacity strategies with respect to total profit; Ref. [15] simulated performance differences between fixed and rolling horizon environments; Ref. [16] analysed the effect of forecast accuracy; Ref. [17] modelled the setting of planned windows and lead times; while Ref. [18] studied the improvement of on-time delivery. These authors report the impact of one or two determinants of a given supply chain function (source, make or deliver) on one or two performance measures. Given that other authors have reported possible trade-offs between different performance measures such as quality consistency, lead time, delivery reliability, cost, and flexibility [19], our postulate is that a given combination of planning determinants from two or more supply chain functions would impact positively or negatively on various SC performance measures, thereby creating a trade-off situation. Ref. [20] noted that, in material requirements planning systems, much was still left to the planner's intuition and experience in selecting appropriate capacity levels and lot sizes for components. Managers therefore need a decision-making support system that would enable them to make the most optimal trade-off decision from an integrated perspective. In a nut shell, this paper aims to study how the integration of supply chain planning determinants impact positively or negatively on supply chain performance objectives.

In the same way that the management of companies involves decisions at the strategic, tactical and operational levels, supply chain planning also involves decisions at these three levels according to the time horizon - long term for strategic planning, medium term for tactical planning and short term for operational planning. However, only the tactical level planning will be studied in this paper for the following reasons: (1) Although Ref. [21] argues that it is crucial for supply chain planning to integrate strategic, tactical and operational decision-making, the huge differences in planning horizons, as well as the difficulty of modelling make the integration (of the three planning levels) to be unrealistic; (2) In recent years, the significance of planning and optimisation at the tactical level has been recognised by academics and practitioners as a competitive advantage for growing production-distribution firms [22]; (3) Dealing with mid-range horizon, the tactical level forms a bridge between the strategic and operational levels [23]; (4) Tactical decisions concern issues surrounding the definition of the more-or-less generic rules for guiding daily operations [24, cited in 25] and these rules tend to satisfy the strategic objectives while respecting the capacities of the supply chain [25]; (5) The tactical level deals with measuring performance against targets to be met in order to achieve results specified at the strategic level [26].

Today, it is commonly admitted that operations planning and control enable firms to be more competitive in many areas, such as quality, delivery, cost efficiency, and flexibility [27]. Moreover, given that this modern world competition is no longer between individual firms, but among supply chains [28], supply chain planning can be considered to be more effective than individual firm operations planning in securing a competitive advantage and improving organisational performance. Therefore, by combining the SCOR model and the customer order decoupling point concept, this paper aims to develop an integrated framework and a fivestep methodology that is used to study the positive, negative and conflicting relationships between tactical supply chain planning determinants and supply chain performance. The paper is organised as follows. Firstly, by reviewing the extant literature, we will clarify the notion of tactical supply chain planning determinants and performance measures. Secondly, by discussing the manner in which the former impacts on the latter, we will formulate our research question. Finally, we will develop and present the integrated framework and the five-step methodology, and then apply them to a numerical example.

\section{Definitions, literature review and research question}

Given that many concepts and terminologies are defined in different ways by different authors, we will in this section state the definitions that we have adopted from extant literature. We will first define supply chain planning and tactical supply chain planning determinants (TSCPDs), then the notion of performance measure (PM), before finally discussing the impact of TSCPDs on PMs.

\subsection{Tactical supply chain planning determinants}

Planning in any business setup is done at three levels according to the time horizon: the strategic level for long-term planning, the tactical level for medium-term planning and the operational level for short-term planning [29]. Depending on the complexity and life cycle of a product, planning time horizons vary considerably from one business sector to another. For example, in the automotive industry, the strategic planning time horizon is about 5-7 years while the tactical planning time horizon is generally one year [30]. In the forest products industry, the horizon of strategic planning is expressed in decades while that of tactical planning is about five years for a forest management problem [21] and varies between six to twelve months for the production scheduling of pulp mills [31]. Operational planning further details the tactical plan and generally focuses on activities on a day-to-day basis [32]. Though the planning decisions at the three levels (strategic, tactical and operational) have been conventionally considered in isolation from the other levels, the interrelation between them is very important in practice [32] and combining aspects of the strategic and tactical levels can make each far more valuable than either would be alone [33]. However, the big difference in time horizons and the dispersed nature of supply chain configuration make this combination more complex and difficult to model. We have therefore chosen in this paper to consider only tactical supply chain planning determinants.

While strategic supply chain planning concerns capacity investments and facility locations [34], tactical supply chain planning addresses allocation rules for resources, as well as usage rules that define production, distribution lead times, lot sizing and inventory policies [21]. It also deals with demand forecasting, production planning, supply planning, replenishment planning and transport planning [32]. According to Ref. [2], the SCOR Plan processes describe the planning activities associated with operating a supply chain. This includes gathering customer requirements, collecting information on available resources, and balancing requirements and resources to determine planned capabilities and resource gaps. It also includes identifying the actions required to correct any gaps. In line with these statements, other authors define tactical supply chain planning as the process that captures information on market demand and inventories, and combines it with supply capabilities and constraints to develop a plan for future volumes [35]. This includes all the parameters associated with demand forecast, procurement of materials, transformation (making), and delivery of finished products to the customer. We refer to these parameters as tactical supply chain planning determinants (TSCPDs).

A review of the contributions of many other authors [5,9,16,35-42] enabled us to identify 12 generic TSCPD. These are planning horizon, frozen time fence, time bucket, cycle time, non-frozen interval, capacity management policy, lot sizing, inventory management policy, Lead time, scheduling, sequencing, and 
Table 1

Definition of tactical supply chain planning determinants.

\begin{tabular}{|c|c|c|}
\hline Planning determinants & Definition & Reference \\
\hline 1. Planning horizon & The number of periods into the future taken into consideration in the planning system. & [9] \\
\hline 2. Frozen time fence & $\begin{array}{l}\text { The interval within the planning horizon, where the timing and quantity of orders are } \\
\text { not permitted to change in the next planning cycle. }\end{array}$ & [42] \\
\hline 3. Time bucket & $\begin{array}{l}\text { A defined period, typically } 7 \text { days, wherein data is summarised for presentation in an } \\
\text { MRP system. }\end{array}$ & [43] \\
\hline 4. Cycle time & The time between the beginnings of two subsequent cycles. & [35] \\
\hline 5. Non-frozen interval & $\begin{array}{l}\text { The interval which extends from the frozen time fence to the end of the planning } \\
\text { horizon, where the timing and/or quantity of orders are permitted to change in the } \\
\text { next planning cycle. }\end{array}$ & [42] \\
\hline $\begin{array}{l}\text { 6. Capacity } \\
\text { management policy }\end{array}$ & $\begin{array}{l}\text { Capacity management policy defines how and when workforce size should be } \\
\text { adjusted. Workforce could be varied, held constant but vary its utilisation by overtime } \\
\text { work or a shortened week, or held constant and produce to stock. }\end{array}$ & [35] \\
\hline 7. Inventory policy & A statement of a company's goals and approach to the management of inventories. & [37] \\
\hline 8. Lot sizing & $\begin{array}{l}\text { The division of the lot into sub-batches that can be transferred to the next operation as } \\
\text { soon as the former operation has been performed for all items. }\end{array}$ & {$[44]$} \\
\hline 9. Lead time & $\begin{array}{l}\text { The time which elapses between the receipt of an order at the point of origin and the } \\
\text { delivery of the goods at the point of consumption. }\end{array}$ & [5] \\
\hline 10. Scheduling & The time or date at which activities are to be undertaken. & [5] \\
\hline 11. Sequencing & $\begin{array}{l}\text { Determining the order in which a manufacturing facility should process a number of } \\
\text { different jobs in order to achieve certain objectives. }\end{array}$ & [37] \\
\hline 12. Forecast accuracy & A reflection of how close previous forecast are to actual demand. & {$[16]$} \\
\hline
\end{tabular}

forecast accuracy. Table 1 summarises the definitions of these determinants.

Given that three of these TSCPDs (inventory policy, lot sizing and lead time) are applicable to the source, make and deliver processes, we have a total of eighteen TSCPDs, which can be grouped together under the four SCOR processes. Each of the TSCPDs is composed of two, three or more tactical options (or values) as can be seen in Table 2. For example, the planning horizon could be short (some weeks), medium (some months) or long (one or two years); material replenishment could be based on a fixed order quantity, fixed period quantity or lot-for-lot policy; while sequencing could be done on the basis of earliest due date, first in first out, last in first out, shortest processing time, longest processing time or critical ratio.

\subsection{Performance measures and metrics}

A performance measure is a metric used to quantify the efficiency and/or effectiveness of an action [45]. Generally speaking, effectiveness is defined as the extent to which goals are accomplished, while efficiency is the measure of how well the expended resources are utilised [46]. One of the key goals of a firm is to sustain growth by satisfying its customers. Therefore, from a business and marketing perspective, effectiveness can be defined as the extent to which customer requirements are met, while efficiency is a measure of how economically the firm's resources are utilised when providing a given level of customer satisfaction [45]. In the supply chain management context, Ref. [47] reviewed the extant literature and identified seven performance measurement frameworks that are based on different criteria. The four most relevant of these criteria are (1) the balanced scorecard perspective [48], which includes four areas - financial, customers, internal process, innovation and growth; (2) components of performance measures [49], which covers four categories - time, resource utilisation, output and flexibility; (3) the location of measures in supply chain links [5], which is built around five categories - planning and product design, supplier, production, delivery and customer; (4) decision-making levels [5], which is broken into the three conventional planning levels - strategic, tactical and operational. Performance measures and metrics should be directly related to a firm's strategy [50], but one weakness of these frameworks is that they do not show how tactical and operational performance metrics can be linked to a firm's strategic goals. Ref. [51] developed a performance pyramid (as shown in Fig. 1) that enables to correct this weakness.

Supply chain management integrates supply and demand management within and across companies, and encompasses the planning and management of all activities involved in sourcing and procurement, conversion, and all logistics management activities [43]. Based on this statement, the criteria for measuring the performance of a supply chain (SC) can be grouped into three categories: those associated with the performance of the upstream activities of the SC (with respect to sourcing and procurement), those used to measure the performance of the internal SC (with respect to conversion or manufacturing operations), and those used to measure the performance of the downstream activities (with respect to delivery), as well as the logistics component of the SC, with the aim of satisfying the customer. The performance measures and metrics

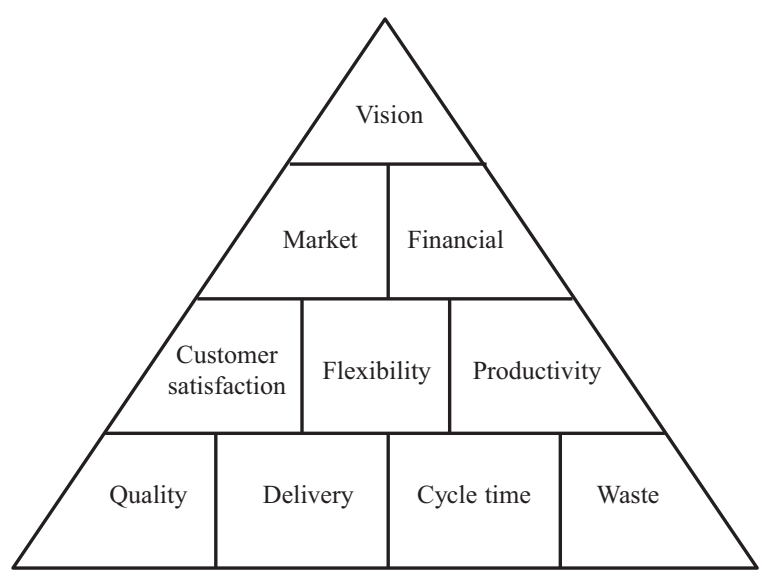

Source: Ref. [51]
Fig. 1. Performance pyramid. 
Table 2

Determining factors of the tactical planning SCOR processes.

\begin{tabular}{ll}
\hline 1. Determinants of the plan process & \\
\hline 1.1 Planning horizon & - Short (monthly) \\
& - Medium (quarterly) \\
& - Long (yearly) \\
1.2 Frozen time fence & - Short (some days) \\
& - Medium (some weeks) \\
& - Long (some months) \\
& - Short (1 day) \\
1.3 Time bucket & - Medium (1 week) \\
& - Long (1 month) \\
1.4 Cycle time & - Short (some days) \\
& - Medium (some weeks) \\
& - Long (some months) \\
1.5 Non-frozen interval & - Liquid order policy \\
& - Slushy order policy
\end{tabular}

2. Determinants of the source process

\begin{tabular}{ll}
\hline 2.1 Lot sizing (replenishment & - Fixed order quantity \\
policy) & - Fixed period quantity \\
& - Period order quantity \\
& - Lot-for-lot \\
& \\
2.2 Inventory policy (materials & - Low safety stock \\
availability) & - Medium safety stock \\
& - High safety stock \\
2.3 Procurement lead time & - Short (some days) \\
& - Medium (some weeks) \\
& - Long (some months)
\end{tabular}

3. Determinants of the make process

3.1 Capacity management policy

- Medium safety stock
3.2 Lot sizing (production quantity policy)

\begin{abstract}
3.3 Inventory policy
(work-in-process policy)
\end{abstract}

3.4 Production lead time

3.5 Scheduling

3.6 Sequencing

- Constant output rate

- Chase demand

- Mixed strategy

- Fixed batch quantity

Fixed period quantity

- Lot-for-lot

- Low safety stock

- High safety stock

- Short (some days)

- Medium (some weeks)

- Long (some months)

- Forward

- Backward

- Earliest Due Date

First In, First Out

- Last In, First Out

- Shortest Processing Time

- Longest Processing Time

- Critical ratio

4. Determinants of the deliver process

\begin{tabular}{ll}
\hline 4.1 Lot sizing (delivery order & - Fixed order quantity \\
quantity) & - Fixed period quantity \\
& - Period order quantity \\
& - Lot-for-lot \\
4.2 Inventory policy (end-product & - Low safety stock \\
availability) & - Medium safety stock \\
& - High safety stock \\
4.3 Delivery lead time & - Short (some days) \\
& - Medium (some weeks) \\
& - Long (some months) \\
4.4 Forecast accuracy & - Low confidence \\
& - Medium confidence \\
& - High confidence
\end{tabular}

used in this paper belong to the last category since order fulfilment is considered a component of the delivery and logistics function.

The aim of the delivery and logistics function is to ensure that the right product is delivered in the right quantity, at the right time, in the right condition (quality), to the right place, with the right documents, and for the right cost [2,52,53]. Possible corresponding performance metrics (or measures) are: delivery item accuracy for right product, delivery quantity accuracy for right quantity, on-time delivery for right time, quality conformance for right condition, delivery location accuracy for right place, documentation accuracy for right document, and delivery efficiency for right cost. Based on the performance pyramid (Fig. 1) of Ref. [51], we can say that these seven performance metrics constitute the quality and delivery performance measures that lead to customers' satisfaction, which in turn contributes to higher market and financial performance, thereby achieving the firm's strategic goals in terms of efficiency and effectiveness. In support of this statement, some authors $[54,55]$ suggest that customer satisfaction implies lower marketing costs, less price elasticity, and higher customer loyalty, which in turn lead to improvements in financial performance measures such as sales revenue and market share.

\subsection{Impact of tactical supply chain planning determinants on performance}

In extant literature, contributions on the impact of tactical supply chain planning determinants (TSCPDs) on performance are very diverse in scope and nature, and most often remain dispersed. Some studies focus on internal job shop performance metrics such as average lateness, average flow time, average tardiness, proportion of tardy jobs, maximum lateness/tardiness, machine utilisation, and work-in-process inventory [56,57]. Ref. [58] reported that reducing the lot size reduces the fraction of defective products. Ref. [59] studied assembly line sequencing problems with the aim of minimising tardiness cost, as well as some other internal performance measures such as costs related to setup, production rate variation, operator idleness, operator error and utility worker. Regarding the authors that looked at the external performance measures, most of the studies focus on the impact of only one or a few determinants (from only one supply chain function - plan, source, make or deliver) on one or a few performance measures. For example, Ref. [60] found that the lengthening of the planning horizon always reduces the global cost. Ref. [61] looked at the relationship between lot size, lead time, inventory, and performance.

Moving a step further, a few authors have studied the impact of a combination of two or more planning determinants on performance measures, but the studied determinants still belong to the same supply chain function (plan, source, make or deliver). For example, Ref. [62] reported that simultaneously reducing setup times and lot sizes was found to be the most effective way to cut inventory levels and improve customer service. Here, both setup times and lot sizes belong to the make (manufacturing) function. After studying the effects of four determinants (capacity, storage time, scheduling and sequencing rules, all belonging to the make function) on the performance of a specific two-stage system, Ref. [13] concluded that, contrary to common sense in operations management, the Longest Processing Time sequencing rule is able to maximise the total production volume per day. Ref. [63] investigated the effectiveness of a tactical demand-capacity management policy to guide decisions in order-driven production systems and found that the dynamic capacity allocation procedure produces higher profit compared to a first-come-first-served policy. Looking at the demand side of a supply network in a configure-to-order environment, Ref. [64] studied the impact of three factors (demand skew, demand variability, and configuration capacity) and observed 
that all the three variables individually and interactively influence customer service performance.

Ref. [42] studied eight factors (non-frozen interval policy, planning horizon length, frozen interval length, re-planning frequency, cycle length, vendor flexibility, demand range and demand lumpiness) and arrived at the conclusion that vendor flexibility and its interactions with Master Production Schedule design factors are the most significant drivers of system performance in two-stage supply chains. Though this study considers determinants from different supply chain functions, it investigates their impact only on internal performance measures. In this paper, we are rather interested not only in combining determinants from different supply chain functions, but also in studying their impact on external performance measures as defined in Section 2.2.

Therefore, beyond the aim of looking at the impact of one or a few TSCPDs on one or a few performance measures, our study constitutes a significant contribution given that it adopts an integrated approach that explicitly analyses the impact of many TSCPDs from different supply chain functions on many (most important) external performance measures. With reference to supply chain planning in the forest products industry, Ref. [21] stated that procurement, production and distribution activities are always bounded by the trade-offs between yield, logistical costs and service levels. Based on this statement, we formulate our research hypothesis as:

Different combinations of tactical planning determinants from two or more supply chain functions (plan, source, make or deliver) would impact differently on a given set of external performance measures.

This hypothesis can be reformulated as a research question in the following manner:

What combination of tactical supply chain planning determinants would enable to optimise supply chain performance, given the possible trade-off between different performance measures?

\section{Methodology and numerical application}

To address our research question, this paper starts by proposing an integrated framework that incorporates the determinants of all the four SCOR process areas (plan, source, make, and deliver), as well as the customer order decoupling point (CODP) concept. The CODP is defined by some authors as the point in the goods flow where forecast-driven production and customer-driven production/delivery are separated [65]. This framework is shown in Fig. 2.

As can be seen in Fig. 2, there are three supply chain configurations - make-to-stock (MTS), make-to-order (MTO) and assemble-to-order (ATO). In the MTS system, the deliver process is downstream of the CODP and therefore demand-driven, while the source and make processes are upstream of the CODP and therefore forecast-driven. In the MTO system, the make and deliver processes are downstream of the CODP and therefore demand-driven, while the source process is upstream of the CODP and therefore forecastdriven. The ATO system is a hybrid system that is mid-way between the MTS and MTO systems. In this system, the deliver process and part of the make process (the final assembly of products) are downstream of the CODP and therefore demand-driven, while the source process and the other part of the make process (the fabrication of semi-finished products) are upstream of the CODP and therefore forecast-driven.

Based on this integrated framework we propose a five-step decision-making methodology that would enable the planning manager to optimise SC performance by identifying the best combination of TSCPDs. The five steps are described as follows.

Step 1: Identify all the planning determinants of the four SCOR process areas (plan, source, make and deliver) and shortlist the most important, taking into consideration the type of production system (make-to-stock, assemble-toorder or make-to-order). Then, define the values of the selected determinants based on the characteristics of the supply chain.

Step 2: Identify all performance measures that are in line with the firm's strategic goals and business environment, and then determine the key performance metrics with respect to the objectives of the supply chain.

Step 3: Identify and choose a modelling/simulation method. See Ref. [22] for a comprehensive review of planning models and techniques that are applied to different supply chain configurations.

Step 4: Develop the optimisation (or decision-making) model, run simulations, and perform some sensitivity analyses.

Step 5: Identify the strongest and weakest combinations of planning determinants by analysing their impact on performance. Then, choose the best (optimal) combination of planning determinants.

To illustrate how the proposed methodology can be applied to a given supply chain configuration, we will start by describing the supply chain that we studied, before presenting the five steps.

\subsection{The supply chain}

In their review of integrated production-distribution (P-D) planning models and techniques, Ref. [22] grouped the identified models into seven categories:

1. Single-product P-D models.

2. Multiple-product, single-plant P-D models.

3. Multiple-product, multiple-plant, single or no warehouse P-D models.

4. Multiple-product, multiple-plant, multiple-warehouse, single or no end-user P-D models.

5. Multiple-product, multiple-plant, multiple-warehouse, multiple-end user, single-transport path P-D models.

6. Multiple-product, multiple-plant, multiple-warehouse, multiple-end user, multiple-transport path, no-time period P-D models.

7. Multiple-product, multiple-plant, multiple-warehouse, multiple-end user, multiple-transport path, multiple-timeperiod P-D models.

The case study used in this paper can be likened to category 3 (multiple-product, multiple-plant, single or no warehouse P-D models) of their classification. In essence, it is a two-stage and two-product supply chain in a make-to-stock environment where production is planned based on demand forecasts (see Fig. 3). The two product groups (shelves and tables) are produced and delivered to end customers. The product structures of the two product groups are simple, with one component at each level. Each production plant in the supply chain makes just one component. The first plant (sawmills) transforms and delivers wooden parts (table legs, table trays and shelf boards) to the assembly plant that constitutes the second and final production stage for the shelves. After assembly, tables are shipped to a third plant for the painting operation. The sawmills, the assembly plant and the painting shop are assumed to collaborate in a dyadic supplier-customer relationship. Each plant is considered to be a single resource with limited capacity. Regarding the supply of raw materials, we assume an ideal situation - constant, regular, and without shortage.

Transportation is required between any two plants. Activities and resources needed for transportation are lumped together such that each transport operation is characterised by a given 


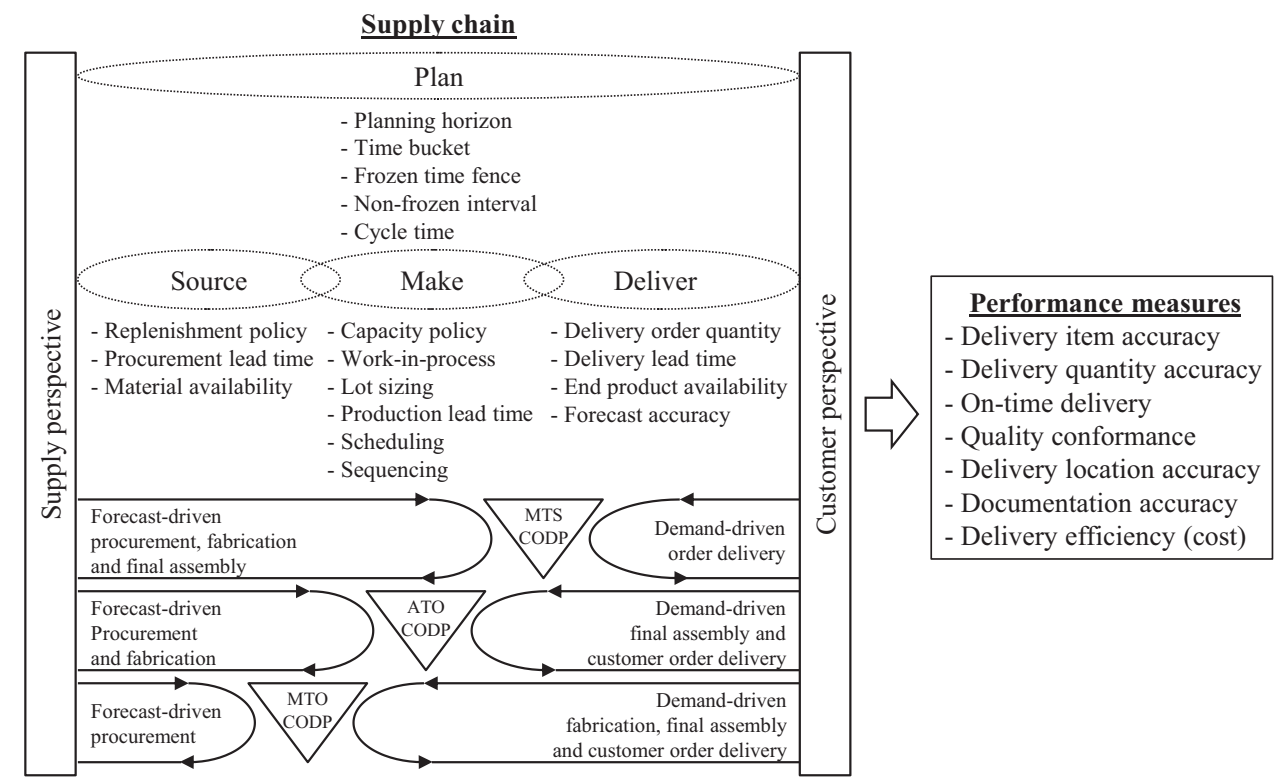

Fig. 2. Integrated tactical supply chain planning determinants based on the SCOR model.

capacity (limiting transfer throughput) and a lead time. Each plant is solely responsible for managing its processes - procurement, production, storage and delivery. We assume that the lead time for the transmission of information is zero.

\subsection{Application of the proposed five-step methodology}

Step 1: Identifying and selecting planning determinants

The framework shown in Fig. 2 serves to identify and select the most relevant determinants for a given supply chain configuration. In this framework, the customer order decoupling point (CODP) is used to distinguish three supply chain configurations: make-tostock (MTS), assemble-to-order (ATO) and make-to-order (MTO). Ref. [66] defined the CODP as the point in the value-adding material flow that separates decision made under uncertainty from decisions made under certainty concerning customer demand. Based on this definition, we can say that the most relevant tactical planning determinants for a given supply chain configuration depend on the one hand on the type of production system - MTS, ATO or MTO (see Ref. [67] for detailed information on the factors that determine the strategic positioning of the CODP) and on the other hand on the factors of uncertainty embedded in the supply chain and its environment.

In MTS systems, based on the forecast of future orders, finished products are produced in advance and kept in inventory, which is then used to fulfil customer orders. This implies that forecast accuracy and end-product availability are determinants that would have a significant impact on the customer order fill rate. In MTO systems, given that production is triggered upon the receipt of a real order from the customer, the primary challenge is how to meet the promised delivery lead time [17,59]. In this case, meeting the promised lead time will largely depend on the procurement and capacity management policies $[17,68]$. Regarding ATO systems, part of production (the final assembly) is triggered upon the receipt of a real customer order, while the other part (procurement and the fabrication of semi-finished products) is carried out based on

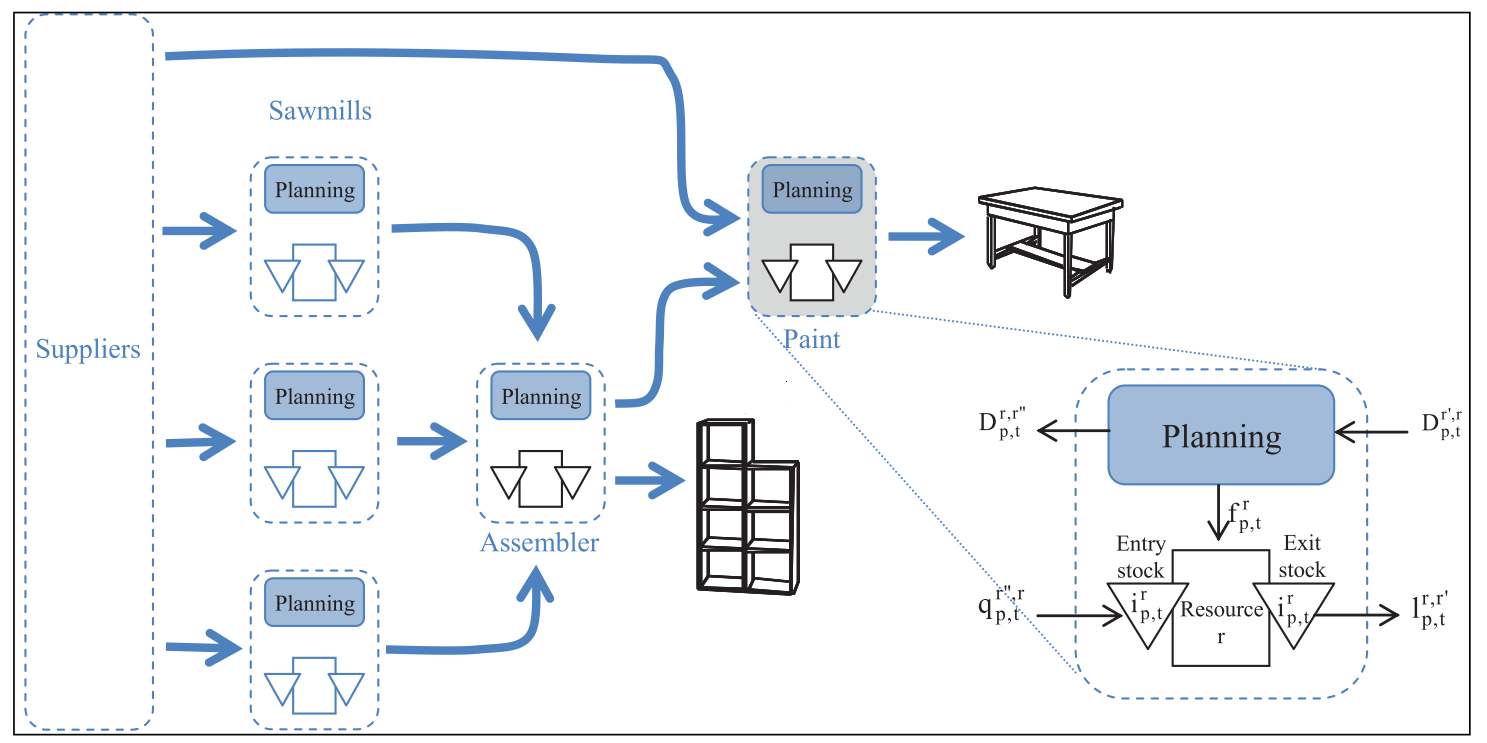

Fig. 3. The supply chain. 
Table 3

Sources of uncertainty.

\begin{tabular}{|c|c|c|}
\hline Uncertainty group & Factors of uncertainty & Description \\
\hline \multirow{6}{*}{$\begin{array}{l}\text { Internal organisational } \\
\text { uncertainty }\end{array}$} & Product characteristics & Product life cycle, packaging, perishability, mix, or specification. \\
\hline & Process/manufacturing & Machine breakdowns, labour problems, process reliability, etc. \\
\hline & Control/chaos/response uncertainty & Uncertainty as a result of control systems in the supply chain. \\
\hline & Decision complexity & $\begin{array}{l}\text { Uncertainty that arises because of multiple dimensions in decision-making } \\
\text { process, e.g. multiple goals, constraints, long term plan, etc. }\end{array}$ \\
\hline & $\begin{array}{l}\text { Organisation structure and human } \\
\text { behaviour }\end{array}$ & E.g. organisation culture. \\
\hline & IT/IS complexity & $\begin{array}{l}\text { The realisation of threats to IT use in the application level, organisational level } \\
\text { and inter-organisational level, e.g. computer viruses, technical failure, } \\
\text { unauthorised physical access, misuse, etc. }\end{array}$ \\
\hline \multirow[t]{6}{*}{$\begin{array}{l}\text { Internal supply chain } \\
\text { uncertainty }\end{array}$} & End customer demand & $\begin{array}{l}\text { Irregular purchases or irregular orders from final recipient of product or } \\
\text { service. }\end{array}$ \\
\hline & Demand amplification & Amplification of demand due to the bullwhip effect. \\
\hline & Supplier & Supplier performance issues, such as quality problems, late delivery, etc. \\
\hline & Parallel interaction & $\begin{array}{l}\text { Parallel interaction refers to the situation where there is interaction between } \\
\text { different channels of the supply chain in the same tier. }\end{array}$ \\
\hline & Order forecast horizon/lead-time gap & $\begin{array}{l}\text { The longer the horizon, the larger the forecast errors and hence there is greater } \\
\text { uncertainty in the demand forecasts. }\end{array}$ \\
\hline & $\begin{array}{l}\text { Chain configuration, infrastructure and } \\
\text { facilities }\end{array}$ & E.g. number of parties involved, facilities used or location, etc. \\
\hline \multirow[t]{2}{*}{ External uncertainties } & Environment & $\begin{array}{l}\text { E.g. political, government policy, macroeconomic and social issues, competitor } \\
\text { behaviour. }\end{array}$ \\
\hline & Disruption/natural uncertainties & E.g. earthquake, tsunamis, non-deterministic chaos, etc. \\
\hline
\end{tabular}

Source: Ref. [69].

forecast. Therefore, key determinants in ATO systems would include the key determinants of MTS and MTO systems.

Regarding the degree of uncertainty of the supply chain, Ref. [69] reviewed the extant literature and identified fourteen sources of uncertainty, which they divided into three groups - internal organisation uncertainty, internal supply chain uncertainty and external uncertainty - as shown in Table 3.

The further the CODP is positioned downstream the more the value-adding activities would be carried out under uncertainty. On the contrary, the more the CODP is positioned upstream, the more the value-adding activities would be carried out under certainty [66]. It follows that the tactical planning determinants to be considered in a given supply chain configuration would depend on the factors of uncertainty that are downstream or upstream of the CODP. For example, in MTS systems, tactical planning determinants would be subject to most of the internal organisation and internal supply chain uncertainty factors since the procurement, fabrication and final assembly activities are upstream of the CODP. However, the selection of the relevant planning determinants would depend on the degree of uncertainty, as well as on the consequences of the uncertainty.

Regarding the supply chain that is used as a case study in this paper, we identified six tactical supply chain planning determinants (TSCPDs): two (frozen time fence and cycle time) from the plan process area, two (capacity management policy and sequencing) from the make process area, and two (end-product availability and forecast accuracy) from the delivery process area. End-product availability and forecast accuracy are chosen since the studied supply chain is an MTS system. For the make process area, we chose to simulate capacity management policy and sequencing since each manufacturing plant is considered to be a single resource with limited capacity. Limited capacity would lead to either shortage or excess inventory following an increase or a decrease in demand forecast. In this case, finding the right sequencing in a multiproducts system would be a crucial issue. Consequently, cycle times will depend on sequencing, and to obtain the best capacity management performance, the frozen time fence has to be optimised. We note that no determinant is chosen from the source process area since we assumed that raw materials are supplied in an ideal situation - constant, regular, and without shortage.

Frozen time fence is simulated by considering different values ( $T=5$ or 10 periods) for the period of replenishment $T$. In this case, the decision making process is dynamically depicted according to the principle of rolling planning horizon. Two cycle times (long and short) are simulated. The transportation lead time stated in Table 4 represents values corresponding to a long cycle time. In this case, transportation cost is assumed to be low (0.03). A short cycle time is $50 \%$ of the long cycle time and implies reducing the transportation lead time by $50 \%$. The transportation cost is therefore higher $(0.1)$.

Two capacity policies are considered for each partner - the "constant output rate" strategy where the production rate is equal to the average demand over the planning horizon, and the "chase demand" strategy in which manufacturing capacity is varied according to demand. We note that the first strategy entails reducing the initial production cost ( $80 \%$ of the nominal cost given in Table 4) whereas in the second strategy, production cost is increased ( $150 \%$ of the nominal cost). We studied two sequencing rules: first-in-first-out (FIFO) where backlogs are processed first before the most recent or incoming customer orders, and last-infirst-out (LIFO), which gives higher priorities to the most recent orders.

Materials or end product availability (or inventory policy) is expressed in terms of safety stock. Two cases are tested: with or without safety stock. Without safety stock means that the parameter $S S_{p}^{r}$ is set to zero. Otherwise, the safety stock is evaluated with the formula: $S S_{p}^{r}=K \sigma_{p}^{r} \sqrt{D}$, where $K$ is a safety factor implied by 
Table 4

Model notations.

\begin{tabular}{|c|c|}
\hline \multicolumn{2}{|l|}{ Parameters } \\
\hline$H$ & Planning horizon \\
\hline$K_{p, p^{\prime}}^{r}$ & Bill of materials coefficients \\
\hline $\begin{array}{c}p P_{p}^{r} \\
\end{array}$ & Production lead time \\
\hline$D L^{p, r^{\prime}}$ & Transportation lead time \\
\hline$\alpha_{p}$ & Quantity of resource required \\
\hline$\beta_{p}$ & Unitary weight or volume \\
\hline$\delta_{p}$ & Space for stocking one unit $p$ \\
\hline $\mathrm{CapR}_{t}^{r}$ & Production capacity \\
\hline $\mathrm{CapS}_{t}^{r}$ & Storage capacity \\
\hline$S S_{p}^{r}$ & Safety stock \\
\hline $\operatorname{CapT}_{t}^{r, r^{\prime}}$ & Transport capacity \\
\hline$A C_{t}^{r}$ & Unitary added capacity cost \\
\hline$C A_{p}^{r}$ & Unitary purchase price \\
\hline$C S_{p}^{p}$ & Unitary average inventory cost \\
\hline$C P_{p}^{r}$ & Unitary average production cost \\
\hline$C B_{p}^{r}$ & Unitary backorder cost \\
\hline$C R_{p}^{r}$ & Unitary shortage cost \\
\hline$C T_{p}^{r}$ & Unitary transportation cost \\
\hline$F_{p}^{r}$ & Fixed production quantity \\
\hline$d_{p, t}^{r, r^{\prime}}$ & Demand of product $p$ during period $t$ from $\mathrm{PU}_{r}$ to $\mathrm{PU}_{r^{\prime}}$ \\
\hline$A L^{r, r^{\prime}}$ & Acceptable delivery lateness of customer $r^{\prime}$ for supplier \\
\hline & $r$ \\
\hline \multicolumn{2}{|l|}{ Indexes } \\
\hline$r, r^{\prime}$ & Index of PU (Production Unit) \\
\hline$p, p^{\prime}$ & Index of products \\
\hline$t$ & Index of planning period \\
\hline \multicolumn{2}{|l|}{ Variables } \\
\hline$i_{p, t}^{r}$ & $\begin{array}{l}\text { Inventory level of product } p \text { in the } \mathrm{PU}_{r} \text { at the end of } \\
\text { period } t \text {, for both semi-finished and finished products }\end{array}$ \\
\hline$(i+)_{p, t}^{r} /(i-)_{p, t}^{r}$ & $\begin{array}{l}\text { Inventory level of product } p \text { in the } \mathrm{PU}_{r} \text { at the end of } \\
\text { period } t \text { upper/lower safety stock }\end{array}$ \\
\hline$b_{p, t}^{r, r^{\prime}}$ & $\begin{array}{l}\text { Quantity of product } p \text { in the } \mathrm{PU}_{r} \text { delivered late to } \\
\text { customer } r^{\prime} \text { at the end of period } t\end{array}$ \\
\hline$b_{p, t}^{r}$ & $\begin{array}{l}\text { Final customers' backorders of product } p \text { in the } \mathrm{PU}_{r} \text { at } \\
\text { the end of period } t\end{array}$ \\
\hline$x_{p}^{r}$ & Quantity of product $p$ never delivered to customer $r$ \\
\hline$f_{p, t}^{r}$ & $\begin{array}{l}\text { Quantity of product } p \text { to be produced in the } \mathrm{PU}_{r} \text { during } \\
\text { period } t\end{array}$ \\
\hline$l_{p, t}^{r, r^{\prime}}$ & $\begin{array}{l}\text { Quantity of product } p \text { delivered during period } t \text { from } \\
\mathrm{PU}_{r} \text { to } \mathrm{PU}_{r^{\prime}}\end{array}$ \\
\hline$q_{p, t}^{r, r^{\prime}}$ & $\begin{array}{l}\text { Quantity of component } p \text { received during period } t \text { at } \\
\text { the } \mathrm{PU}_{r} \text { from } \mathrm{PU}_{r^{\prime}}\end{array}$ \\
\hline$y_{t}^{r}$ & Added capacity needed in the PU during period $t$ \\
\hline
\end{tabular}

the specified service level (abacus), $\sigma_{p}^{r}$ is the standard deviation of the demand in the resource $r$, and $D$ represents the replenishment lead time. $D$ can be transportation lead time for materials or production lead time for end products. Finally, two situations of forecast accuracy are simulated: a fairly accurate forecast where actual demand varies only slightly with respect to forecasts and a low confidence forecast where actual demand is subjected to huge variations compared to the forecasts.

\section{Step 2: Identifying and determining performance measures and} metrics

In Section 2.2, we identified seven performance measures for an order fulfilment process: delivery item accuracy, delivery quantity accuracy, on-time delivery, quality conformance, delivery location accuracy, documentation accuracy and delivery efficiency. In the case of the supply chain that we studied, four of these measures (delivery item accuracy, quality conformance, delivery location accuracy, and documentation accuracy) are considered to be second-order performance measures since a high or low performance on these parameters would impact the other three measures. For example, the delivery of defective or wrong products at a wrong location and with incomplete (or wrong) documents would negatively impact on cost and on-time-delivery of the right products. We have therefore simulated only three measures (delivery efficiency, delivery quantity accuracy, and on-time delivery), which we consider as first-order measures. These three performance measures are mentioned by Ref. [70] as the primary goal of supply chain planning. In this paper, they are defined in the following manner:

- Delivery efficiency is measured in terms of profit margin. An efficient system aims to minimise cost, thereby maximising profit. In this study, we normalised this metric by taking the highest profit as $100 \%$ and then calculating the others with respect to it.

- Delivery quantity accuracy is measured in terms of the percentage of ordered quantities that are delivered within a given time frame.

$S R_{p, r^{\prime}, r}=\frac{\sum_{H} l_{p, t}^{r, r^{\prime}}}{\sum_{H} d_{p, t}^{r, r^{\prime}}}$

Its value goes from 0 to $100 \%$, the latter being the best. $0 \%$ means that nothing is delivered on time and $100 \%$ means that all the ordered quantities are delivered on time. We will refer to this metric as "Completeness".

- On-time delivery is measured as the Normalised Average Delivery Time (NADT) of the total quantity that is delivered.

$\mathrm{NADT}_{p, t, r^{\prime}, r}=\frac{\sum_{i=0}^{\mathrm{AL}^{r}, r^{\prime}} \frac{\mathrm{AL}^{r, r^{\prime}}-i}{\mathrm{AL}^{r, r^{\prime}}} l_{p, t+i}^{r, r^{\prime}}}{d_{p, t}^{r, r^{\prime}}}$

where $\mathrm{AL}^{\mathrm{r}, \mathrm{r}^{\prime}}$ is the acceptable delivery lateness of customer $r^{\prime}$ from supplier $r$. For all quantity delivered on time (on the due date), $\mathrm{AL}=100 \%$ and for those delivered after the period of acceptable delivery lateness, $\mathrm{AL}=0$.

For example, let us consider an order of 10 units of a product to be delivered on day 1 (due date), with a maximum acceptable lateness of 3 days beyond the due date. If 3 units are delivered on day 1,3 on day 2,1 on day 3,1 on day 4 , and 2 on day 5 , on-time delivery is equal to $60 \%$. This is obtained by calculating the NADT as follows:

$$
\begin{aligned}
\text { NADT }= & \frac{[(3 \times 1)+(3 \times 0.75)+(1 \times 0.5)+(1 \times 0.25)+(2 \times 0)]}{10} \\
& \times 100 \%=60 \%
\end{aligned}
$$

Being normalised, the value of NADT must be between 0 and $100 \%$, the latter being the best. A value of 100 means that $100 \%$ of the ordered quantity was delivered on or before the due date; a value close to 100 signifies that a high percentage of the ordered quantity was delivered on or before the due date and/or that most of the delivery was done (quickly) on the first day after the due date; while a value close to 0 signifies that most of the delivery was done (lately) on or after the last day of the period of the acceptable delivery lateness.

\section{Step 3: Choosing a model}

In the operations management literature, there are two types of models:

- Analytical models (deterministic or stochastic), which are used to study the behaviour of a supply chain using a mathematical approach [71].

- Simulation models, which are used in analysing complex systems whose state changes with time and/or in a random manner [72] and where analytical models are not easy to apply since they require strong assumptions in order to reduce complexity.

Given the holistic and integrated (complex) nature of our study, we will use the simulation approach to study the impact of the tactical planning determinants on performance. However, we will 
first use a deterministic analytical approach to model the system because analytical models make it easy to see the time horizon as a set of time periods, as used in planning approaches especially for rolling horizon experiments. In our model, the simulation of the planning decision-making process performed by each partner (also called Production Unit and noted PU) in the supply chain is done by solving a generic linear programming model.

\section{Step 4: Model development and simulation}

The proposed model defines optimal plans under storage, production and transportation capacity constraints. Prior to formulating the mathematical model that enables to determine an optimal plan, the following assumptions are made: (1) each PU is associated to one resource $r$ and manufactures a set of products $p$, (2) each resource has an inbound inventory of components and an outbound inventory of semi-finished or finished products, (3) suppliers of suppliers are considered as very reliable, with complete and on-time deliveries, and (4) backorders concern only products delivered to end customers. The notations used to describe the model are summarised in Table 4.

The model plans production, inventory levels, replenishment and delivery according to customers' orders. The objective function is a cost function that aims to minimise costs related to production, inventory, purchasing, shortages (orders that are considered not to have been delivered at the end of the customer's acceptable delivery lead time) and backorders (late deliveries).

$$
\begin{aligned}
\min C_{f}= & \sum_{t}\left(\sum_{r^{\prime}} \sum_{r} \sum_{p}\left(q_{p, t}^{r, r^{\prime}} \cdot C A_{p}^{r}\right)\right. \\
& \left.+\sum_{r}\left(\sum_{p^{\prime}}\left((i+)_{p^{\prime}, t}^{r}+5 \cdot(i-)_{p^{\prime}, t}^{r}\right) \cdot C S_{p^{\prime}}^{r}+\sum_{p}\left(f_{p, t}^{r} \cdot C P_{p}^{r}+b_{p, t}^{r} \cdot C B_{p}^{r}+X_{p}^{r} \cdot C R_{p}^{r}+l_{p, t}^{r} \cdot C T_{p}^{r}\right)+y_{t}^{r} \cdot A C_{t}^{r}\right)\right)
\end{aligned}
$$

The above objective function is solved subject to 7 constraint functions as follows.

Eqs. (4a) and (4b) represent the evolution of inventory levels. Eq. (4a) concerns the finished products: the quantity resulting from the production at a period $t$ corresponds to a production order released a few periods before (depending on the production lead time DP). Eq. (4b) evaluates the inventory levels of each component according to the quantities received by suppliers and quantities consumed by production, based on coefficients in the bill of materials. Given that in a supply chain, the end product of a production unit becomes a component for the downstream production unit, we use the same index $p$ for both components and finished products. Therefore, in Eq. (4a), $i_{p, t}^{r}$ means inventory level of finished product $p$ in production unit $r$ at the end of period $t$, whereas in Eq. (4b), $i_{p, t}^{r}$ stands for the inventory level of component (product) $p$ in the production unit $r$ at the end of period $t$.

$i_{p, t}^{r}=i_{p, t-1}^{r}+f_{p, t-D P_{p}^{r}}^{r}-\sum_{r^{\prime}} l_{p, t}^{r, r^{\prime}}, \quad \forall p, t, r$

$i_{p, t}^{r}=i_{p, t-1}^{r}+\sum_{r^{\prime}} q_{p, t}^{r^{\prime}, r}-\sum_{p^{\prime}}\left(K_{p, p^{\prime}}^{r} \times f_{p^{\prime}, t}^{r}\right), \quad \forall p, t, r$

Eq. (5) expresses backorders, that is, the difference between the quantity ordered by customers and the quantity actually delivered.

$b_{p, t}^{r, r^{\prime}}=b_{p, t-1}^{r, r^{\prime}}+d_{p, t}^{r^{\prime}, r}-l_{p, t}^{r, r^{\prime}}-x_{p, t}^{r, r^{\prime}}, \quad \forall p, t, r, r^{\prime}$

Eqs. (6a), (6b) and (6c) represent respectively capacity restrictions for production, inventory and transportation. The use of an operational costs. additional capacity for production is allowed but requires higher

$\sum_{p}\left(\alpha_{p} \cdot \sum_{\tau=1}^{D P_{p}^{r}} f_{p, t-\tau+1}^{r}\right) \leq \operatorname{CapR}_{t}^{r}+y_{t}^{r}, \quad \forall t, r, r^{\prime}$

$\sum_{p \in P^{r}} \delta_{p} \cdot i_{p, t}^{r} \leq$ CapS $^{r}, \quad \forall t, r, r^{\prime}$

$\sum_{p \in \hat{P}^{r}} \beta_{p} \cdot l_{p}^{r, r^{\prime}} \leq \operatorname{CapT}^{r, r^{\prime}}, \quad \forall t, r, r^{\prime}$

Eq. (7) represents the upper bound of the additional capacity.

$Y_{t}^{r} \leq \mathrm{CAP}_{\text {SUPP }}, \quad \forall p, t, r$

Eqs. (8a) and (8b) represent the lower and upper boundaries of the safety stock threshold.

$(i+)_{p, t}^{r}-(i-)_{p, t}^{r}=i_{p, t}^{r}-S S_{p}^{r}, \quad \forall p, t, r$

$(i-)_{p, t}^{r} \leq S S_{p}^{r}, \quad \forall p, t, r$

Eq. (9) is activated only if the state of the capacity policy determinant corresponds to "constant output rate" (entire COR =1). In this case, the material flow is fixed as the mean value of the production capacity.

$\left(f_{p, t}^{r}=F_{p}^{r}\right) \quad \forall p, t, r$

Finally, Eq. (10) corresponds to the non-negativity constraints for $q_{p, t}^{r, r^{\prime}}, i_{p, t}^{r},(i+)_{p, t}^{r},(i-)_{p, t}^{r}, b_{p, t}^{r, r^{\prime}}, l_{p, t}^{r, r^{\prime}}, y_{t}^{r} \geq 0, \quad \forall p, t, r$

The data used for the simulation are presented in Table 5 .

Concerning the suppliers, their production lead time is included in the transportation lead time and they have no backorders. For all the supply chain partners, the additional production capacity (additional capacity) is infinite and its unit cost is $50 \%$ higher than that of the normal capacity. For each of the companies, the inventory capacity is equal to 5000 units, the delivery transportation capacity is 3000 units per period and the transportation lead time is 1 or 2 periods depending on the cycle time (short or long).

Each simulation runs in a rolling horizon of 40 periods, with specific parameter values for the tested determinants - two possible states for each determinant. Each combination corresponds to one simulation scenario. By changing the value of one determinant at a time we performed 64 simulations. These simulations enabled us to assess the impact of the six determinants (frozen time fence, cycle time, capacity policy, sequencing, materials availability, and forecast accuracy) on the three performance metrics (profit margin, completeness, and NADT). The profit margin, NADT and completeness were determined for each of the supply chain partners. The total values for each of these three performance metrics were computed for the whole supply chain. For the sake of simplicity, we will not present the details for each plant, but only the total values: total profit, total NADT for shelves, total completeness for shelves, total NADT for tables and total completeness for tables. Also, given the high number of simulations performed, we consider that a sensitivity analysis in not necessary since different values of the determinants are tested in the various combinations. 
Table 5

Simulation data.

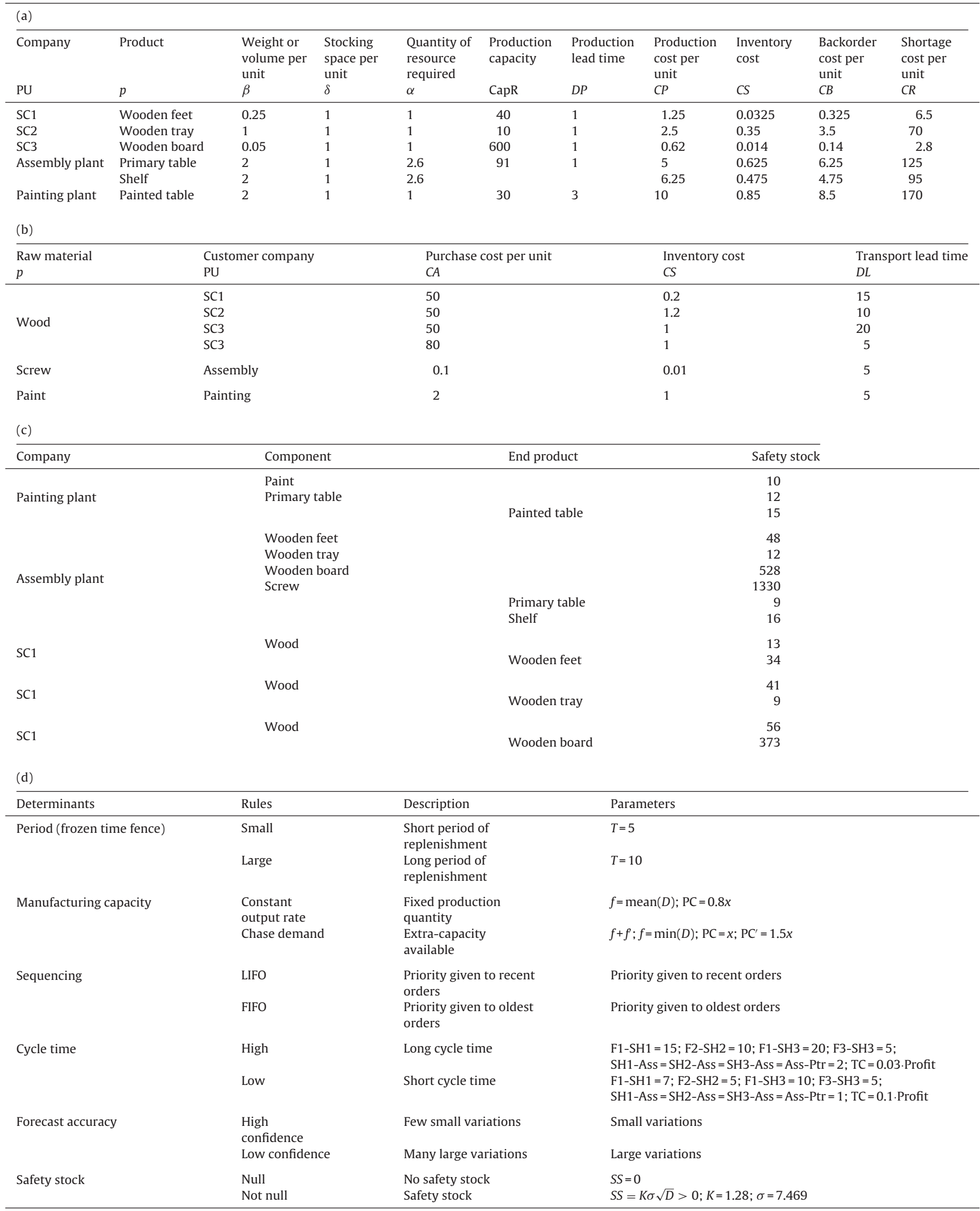




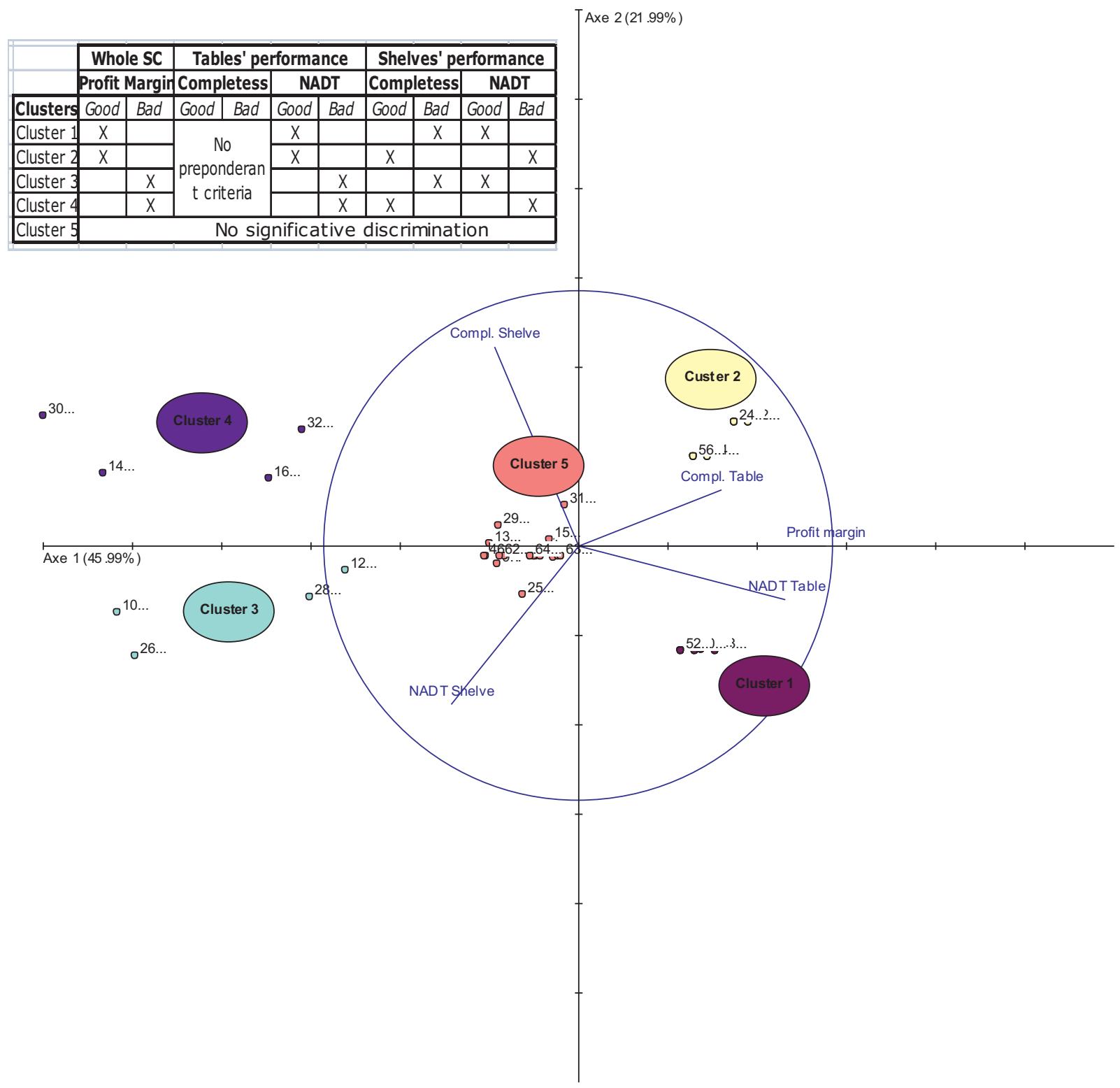

Fig. 4. PCA factorial plan and cluster analysis.

Moreover, sensitivity analyses would be more valuable in a real world business application with real data.

Step 5: Analysis of the simulation results and decision making

Given that this paper aims to explain the relationship between combinations of determinants (simulation scenarios) and performance measures (simulation results), we have chosen to use the Principle Component Analysis (PCA) to analyse our results since it enables to highlight key quantitative variables that explain the major quantitative differences between the simulation scenarios (especially the effect of scale). A global analysis was performed in order to define clusters of the performance results of the simulation scenarios. Based on this, we assessed the common characteristics of the scenarios that composed a cluster in order to highlight the key determinants that can explain the differences between the clusters. In other words, a PCA was carried out on the whole of the numerical variables used in our study: 64 simulations and 5 characters (profit, completeness for tables, NADT for tables, completeness for shelves, and NADT for shelves). As can be seen in Table 6, two axes represent about $70 \%$ of the information and can consequently be interpreted.

The first axis shows that the global profit margin character and the performances on the characters of tables (NADT and in a lesser manner completeness) are closely related. It appears so because tables are more profitable than shelves. If the NADT is good on this product then the profit will equally be good. We also note that no character is really opposed to this trend. The second axis shows for shelves some discrimination between the simulations that have a high level of performance in terms of completeness and those that maximise the NADT performance level.

The PCA singled out five clusters as shown in Fig. 4. We note that cluster no. 5 is not really significant. Its central position indicates that no character of the factorial plan allows isolating the results of the simulation from the others. In other words, cluster no. 5 constitutes the "weak underbelly" of our study. We therefore focus our analysis on the first four clusters.

In order to identify the effect of each determinant on the performance of the supply chain, we first analysed the detailed characteristics of each of the simulations that composed the 
Table 6

PCA analysis: what the axes imply.

\begin{tabular}{|c|c|c|c|c|}
\hline & Axis $1(+45.99 \%)$ & & Axis $2(+21.99 \%)$ & \\
\hline \multirow[t]{3}{*}{ Positive impacts } & Profit margin & $+41 \%$ & Completeness: shelve & $+55 \%$ \\
\hline & NADT: table & $+29 \%$ & Completeness: table & $+4 \%$ \\
\hline & Completeness: table & $+13 \%$ & & \\
\hline \multirow[t]{2}{*}{ Negative impacts } & NADT: shelve & $-11 \%$ & NADT: shelve & $-35 \%$ \\
\hline & Completeness: shelve & $-4 \%$ & NADT: table & $-4 \%$ \\
\hline
\end{tabular}

clusters. Then we compared all the scenario characteristics of a cluster and associated them to the overall performance of the considered cluster. Consequently, by analysing the reasons that justify the discriminations between clusters no. 1, 2, 3 and 4, we clearly observed that the determinants that have the most important effect on performance are manufacturing capacity and sequencing.

Manufacturing capacity has a strong impact on profit margin. The constant output rate strategy gives the best profit margin whereas the chase demand strategy is associated with the worst scenarios in terms of profit margin. It means that the former enables an optimal use of production resources. Also, inventory costs are generally lower than the production costs associated with the additional capacity. Considering the six determinants that we studied, these observations provide a first answer to our research question. We can say that manufacturing capacity is the predominant determinant that impacts on delivery efficiency.

The sequencing determinant has a strong impact on completeness and NADT. In the case of the FIFO rule, completeness increases whereas in the case of the LIFO rule, NADT increases. This can be explained by the fact that with the FIFO rule, the supply chain gives priority to backlogs and consequently minimises late deliveries (shortages), thereby maximising the delivery quantity accuracy of the supply chain. With the LIFO rule, the supply chain gives priority to the most recent customer orders and therefore maximises the on-time delivery performance measure. We note that with the FIFO rule, the service level (expressed as completeness and NADT) is moderate for the whole population of customers while with the LIFO rule, the service level is maximised only for a subset of customers. These observations constitute a second answer to our research question. In essence, among the six determinants that we studied, we can say that sequencing is the predominant determinant as regards to delivery quantity accuracy and on-time-delivery.

All the other determinants have a limited impact on performance. However by analysing the PCA results, we noticed several positive and negative impacts of planning determinants on different performance metrics. For example, we observed that a low confidence on forecast leads to poor profit margins. But, when combined with the constant output strategy, this determinant does not have any impact on performance (see cluster no. 4 in Fig. 4). Also, cycle time appears to be a very significant variable that impacts on the performance of the whole supply chain. In fact, reducing the cycle time generally induces additional costs. But in our set of simulations, the PCA analysis (see cluster no. 3 in Fig. 4) shows clearly that these additional costs could offset the penalties associated with a poor service level. This is the reason why practitioners should consider the cycle time as a very interesting and effective variable for improving the performance of their supply chain. Furthermore, the safety stock parameter improves (more or less) the situation of the most critical cases (see Clusters no. 3 and 4 in Fig. 4). But, if the performance results are globally satisfactory, then safety stock does not limit performance. In other words, safety stocks would not jeopardise benefits if there are no significant disruptions in the supply chain. Finally, the PCA analysis does not permit to reach any significant conclusion regarding the impact of planning horizon on performance. This probably indicates that this determinant is not preponderant compared to the others.
Though the simulations in this paper are performed on only one supply chain configuration, the preliminary results enable to validate our research hypothesis, which states that different combinations of tactical planning determinants from two or more supply chain functions (plan, source, make or deliver) would impact differently on a given set of external performance measures. It follows that in tactical supply chain planning, the optimal combination of determinants would be decided based on the desired performance of the supply chain. In the case of the supply chain that we studied in this paper, the decision would be to lay emphasis on manufacturing capacity, sequencing and cycle time as the preponderant and performance-sensitive determinants.

\section{Conclusion}

The contribution of this paper is threefold. Firstly, by combining the SCOR model and the CODP concept, it develops an integrated framework that would enable researchers to study the relationship between tactical supply chain planning determinants and performance measures, for different manufacturing configurations (make-to-stock, assemble-to-order and make-to-order). Secondly, it proposes a five-step decision-making approach that would enable managers (and computer software programmers) to choose the best combination of tactical planning determinants that would lead to a good (optimal) balance between conflicting performance measures. Thirdly, using a mathematical model and computer simulations, it successfully shows a numerical application of the proposed methodology.

Though Ref. [3] used the SCOR model to study the impact of planning on performance by evaluating each of the process areas - source, make and deliver, the authors did not detail the determinants of the planning process. Using the SCOR model, Ref. [4] also studied and confirmed a positive relationship between all the process areas and supply chain performance, but did not investigate the impact of the determinants of these process areas. The contribution of this paper is therefore unique in two aspects: (1) To the best of our knowledge, this is the first paper that presents an exhaustive list of tactical planning determinants within an integrated framework; (2) It proposes and applies a methodology that enables to investigate the relationship between supply chain performance and various combinations of determinants from all the four SCOR process areas (plan, source, make and deliver). Our results show how different combinations of tactical planning determinants impact on three different supply chain performance metrics (delivery efficiency, delivery quantity accuracy, and on-time delivery).

From a theoretical perspective, this framework can be used to study and develop theories that could explain the trade-offs and mediating roles between planning determinants. For example, Ref. [73] studied how one planning determinant (forecast errors) can be mitigated by another determinant (lot sizing rules). With our proposed framework and methodology, similar studies can now be carried out with many determinants at the same time. Also, the practical implication is that managers can more frequently review their planning parameters according to changes in the level of uncertainty linked to the characteristics of the supply chain, as well as to its environment. 
Though these results are fairly significant, more work is obviously needed since we were limited by the capacity of the software that we used for the simulations. More refined results will certainly require very robust models that might be difficult to simulate, especially if more determinants are simulated and less assumptions are made regarding material flows and supply chain variability. Therefore, challenging areas for future research will entail simulating more than six planning determinants from the four SCOR process areas and for different levels of uncertainty. Furthermore, our framework and methodology can be used to study and compare different supply chain configurations - maketo-stock, assemble-to-order and make-to-order. The models could also be tested for different industrial sectors (and different kinds of products) and market environments. Finally, it could also be challenging to use this framework to study the impact of tactical supply chain planning determinants on both internal and external performance measures.

\section{References}

[1] Lambert DM, Cooper MC, Pagh JD. Supply chain management: implementation issues and research opportunities. Int J Logist Manag 1998;9:1-19.

[2] SCC (Supply Chain Council). Supply-Chain Operations Reference: model overview, version 10.1; 2012. http://supply-chain.org/scor [accessed 09.01.12].

[3] Bronzo M, Valadares de Oliveira MP, McCormack K. Planning, capabilities, and performance: an integrated value approach. Manage Decis 2012;50:1001-21.

[4] Li L, Su Q, Chen X. Ensuring supply chain quality performance through applying the SCOR model. Int J Prod Res 2011;49:33-57.

[5] Gunasekaran A, Patel C, Tirtiroglu E. Performance measures and metrics in a supply chain environment. Int J Oper Prod Manage 2001;21: $71-87$.

[6] Mungan D, Yu J, Sarker BR. Manufacturing lot-sizing, procurement and delivery schedules over a finite planning horizon. Int J Prod Res 2010;48: 3619-36.

[7] Jones CH. Parametric production planning. Manage Sci 1967:18:843-66.

[8] Lockamy III A, McCormack K. Linking SCOR planning practices to supply chain management: an exploratory study. Int J Oper Prod Manage 2004; $24: 1192-218$

[9] Wacker JG, Sheu C. Effectiveness of manufacturing planning and control systems on manufacturing competitiveness: evidence from global manufacturing data. Int J Prod Res 2006;44:1015-36.

[10] Olhager J, Selldin E. Manufacturing planning and control approaches: market alignment and performance. Int J Prod Res 2007;45:1469-84

[11] Tsubone $\mathrm{H}$, Ohba M, Uetake T. The impact of lot-sizing and sequencing on manufacturing performance in a two-stage hybrid flow shop. Int J Prod Res 1996;34:3037-53.

[12] Berkley BJ. The effect of buffer capacity and sequencing rules on single-card kanban system performance. Int J Prod Res 1993;31:2875-93.

[13] Akkerman R, van Donk DP, Gaalman G. Influence of capacity- and timeconstrained intermediate storage in food production systems. Int J Prod Res 2007;45:2955-73.

[14] Jamalnia A, Feili A. A simulation testing and analysis of aggregate production planning strategies. Prod Plan Control 2013;24:423-48.

[15] Feng Y, D’Amours S, Beauregard R. Simulation and performance evaluation of partially and fully integrated sales and operations planning. Int J Prod Res 2010;48:5859-83.

[16] Smith CD, Mentzer JT. User influence on the relationship between forecast accuracy, application and logistics performance. J Bus Logist 2010:31:159-77.

[17] Teo C-C, Bhatnagar R, Graves SC. Setting planned lead times for a maketo-order production system with master schedule smoothing. IIE Trans $2011 ; 43: 399-414$

[18] Karim MA, Samaranayake P, Smith AJR, Halgamuge SK. An on-time delivery improvement model for manufacturing organisations. Int J Prod Res 2010;48:2373-94

[19] Mapes J, New C, Szwejczewski M. Performance trade-offs in manufacturing plants. Int J Oper Prod Manage 1997;17:1020-33.

[20] Bahl HC, Ritzman LP. An integrated model for master scheduling, lot sizing and capacity requirements planning. J Oper Res Soc 1984;35:389-99.

[21] D’Amours S, Rönnqvist M, Weintraub A. Using operational research for supply chain planning in the forest products industry and paper industry. Inform Syst Oper Res 2008;46:265-81.

[22] Fahimnia B, Farahani RZ, Marian R, Luong L. A review and critique on integrated production-distribution planning models and techniques. J Manuf Syst 2013;32:1-19.

[23] Schmidt G, Wilhelm WE. Strategic, tactical and operational decisions in multinational logistics networks: a review and discussion of modelling issues. Int J Prod Res 2000;38:1501-23.

[24] Frayret JM, Boston K, D’Amours S, LeBel L. The E-nable supply chain: opportunities and challenges for forest business. Working paper DT-2004-JMF-1. Québec, Canada: Université Laval; 2004.
[25] Ouhimmou M, D’Amours S, Beauregard R, Ait-Kadi S, Chauhan SS. Furniture supply chain tactical planning optimization using a time decomposition approach. Eur J Oper Res 2008;189:952-70.

[26] Gunasekaran A, Patel C, McGaughey RE. A framework for supply chain performance measurement. Int J Prod Econ 2004;87:333-47.

[27] Olhager J. Evolution of operations planning and control: from production to supply chains. Int J Prod Res 2013;51:6836-43.

[28] Trkman P, McCormack K, Valadares de Oliveira MP, Ladeira MB. The impact of business analytics on supply chain performance. Decis Support Syst 2010;49:318-27.

[29] Chopra S, Meindl P. Supply chain management: strategy, planning, and operation. USA: Pearson, Prentice-Hall; 2004.

[30] Bihlmaier R, Koberstein A, Obst R. Modeling and optimizing of strategic and tactical production planning in the automotive industry under uncertainty. OR Spectrum 2009;31:311-36.

[31] Carlsson D, D’Amours S, Martel A, Rönnqvist M. Supply chain planning models in the pulp and paper industry. Inform Syst Oper Res 2009;47:167-83.

[32] Ivanov D. An adaptive framework for aligning (re)planning decisions on supply chain strategy, design, tactics, and operations. Int J Prod Res 2010;48:3999-4000.

[33] Sodhi MS. How to do strategic supply chain planning. MIT Sloan Manage Rev 2003;Fall:69-75.

[34] Kauder S, Meyr H. Strategic network planning for an international automotive manufacturer: balancing flexibility and economic efficiency. OR Spectrum 2009;31:507-32.

[35] Kaipia R. Effects of delivery speed on supply chain planning. Int J Logist Res Appl 2008;11:123-35.

[36] Stadtler H, Kilger C, editors. Supply Chain Management and Advanced Planning: concepts, models, software, and case studies. 4th ed. Verlag Berlin Heidelberg: Springer; 2008

[37] Arnold T, Chapman SN. Introduction to material management. 4th ed. New ersey: Prentice Hall; 2001

[38] Handfield RB, Nichols EL. Supply Chain Redesign: transforming supply chains into integrated value systems. New Jersey: Financial Times Prentice Hall; 2002.

[39] Simchi-Levi D, Kaminsky P, Simchi-Levi E. Designing and managing the supply chain: concepts, strategies and case studies. 2nd International ed. New York: McGraw-Hill/Irwin; 2003.

[40] Chase RB, Jacobs FR, Aquilano NJ. Operations management for competitive advantage. New York: McGraw-Hill; 2004.

[41] Slack N, Chambers S, Johnston R. Operations management. London: Prentice Hall; 2007.

[42] Robinson Jr EP, Sahin F, Gao L-L. Master production schedule time interval strategies in make-to-order supply chains. Int J Prod Res 2008;46:1933-54.

[43] CSCMP (Council of Supply Chain Management professionals). Supply chain management terms and glossary; 2012. http://cscmp.org/digital/glossary/ document [assessed 09.01.12].

[44] Riezebos J. Time bucket length and lot-splitting approach. Int J Prod Res 2004; $42: 2325-38$

[45] Neely A, Gregory M, Platts K. Performance measurement system design: a literature review and research agenda. Int J Oper Prod Manage 1995;15:80-116.

[46] Mentzer JT, Konrad BP. An efficiency/effectiveness approach to logistics performance analysis. J Bus Logist 1991:12:33-61.

[47] Gunasekaran A, Kobu B. Performance measures and metrics in logistics and supply chain management: a review of recent literature (1995-2004) for research and applications. Int J Prod Res 2007;45:2819-40,

[48] Kaplan RS, Norton DP. The balanced scorecard: measures that drive performance. Harvard Bus Rev 1992;70:71-99.

[49] Beamon BM. Measuring supply chain performance. Int J Oper Prod Manage 1999;19:275-92.

[50] Maskell B. Performance measures for world class manufacturing. Manage Account 1989;67:32-3.

[51] Lynch RL, Cross KF. Measure up - the essential guide to measuring business performance. London: Mandarin; 1991;

Neely A, Bourne M, Kennerley M. Performance measurement system design: developing and testing a process-based approach. Int J Oper Prod Manage 2000;20:1119-45.

[52] Aghazadeh S-M. Improving logistics operations across the food industry supply chain. Int J Contemp Hosp Manage 2004;16:263-8.

[53] Bhagwat R, Sharma MK. Performance measurement of supply chain management using the analytical hierarchy process. Prod Plan Control 2007:18:666-80.

[54] Anderson EW, Formell C, Rust RT. Customer satisfaction, productivity and profitability: differences between goods and services. Mark Sci 1997;16:129-45.

[55] Rust RT, Zahorik AJ. Customer satisfaction, customer retention, and market share. J Retail 1993;69:193-215.

[56] Chandra P. Mehta P. Tirupati D. Permutation flow shop scheduling with earliness and tardiness penalties. Int J Prod Res 2009;47:5591-610.

[57] Randhawa SU, Zeng Y. Job shop scheduling: an experimental investigation of the performance of alternative scheduling rules. Prod Plan Control 1996; 7:47-56.

[58] Porteus EL. Optimal lot sizing, process quality improvement and setup cost reduction. Oper Res 1986;34:137-44

[59] Manavizadeh N, Tavakoli L, Rabbani M, Jolai F. A multi-objective mixedmodel assembly line sequencing problem in order to minimize total costs in a make-to-order environment, considering order priority. J Manuf Syst 2013;32:124-37. 
[60] Galasso F, Merce C, Grabot B. Decision support for supply chain planning under uncertainty. Int J Syst Sci 2008;39:667-75.

[61] Enns ST. MRP performance effects due to lot size and planned lead time settings. Int J Prod Res 2001:39:461-80.

[62] Krajewski LJ, King BE, Ritzman LP, Wong DS. Kanban, MRP, and shaping the manufacturing environment. Manage Sci 1987;33:39-57.

[63] Barut M. Revenue management in order-driven production systems. Decis Sci 2005;36:287-316.

[64] Ngaya GN, Closs DJ, Rodrigues A, Calantone RJ. The impact of demand uncertainty and configuration capacity on customer service performance in a configure-to-order environment. J Bus Logist 2007;28:83-104.

[65] Giesberts PMJ, van den Tang L. Dynamics of the customer order decoupling point: impact on information systems for production control. Prod Plan Control 1992;3:300-13.

[66] Rudberg M, Wikner J. Mass customization in terms of the customer order decoupling point. Prod Plan Control 2004;15:445-58.

[67] Olhager J. Strategic positioning of the order penetration point. Int J Prod Econ 2003;85:319-29.
[68] Rafiei H, Rabbani M. Capacity coordination in hybrid make-to-stock/make-toorder production environments. Int J Prod Res 2012;50:773-89.

[69] Simangunsong E, Hendry LC, Stevenson M. Supply-chain uncertainty: a review and theoretical foundation for future research. Int J Prod Res 2012;50:4493-523.

[70] Steinrücke M, Jahr M. Tactical planning in supply chain networks with customer oriented single sourcing. Int J Logist Manage 2012;23: 259-79.

[71] Ganeshan R, Jack E, Magazine MJ, Stephens P. A taxonomic review of supply chain management research. In: Tayur S, Ganeshan R, Magazine M, editors. Quantitative models for supply chain management. Boston: Kluwer Academic Publishers; 1999.

[72] Angerhofer BJ, Angelides MC. System dynamic modelling in supply chain management: research review. In: Joines JA, Barton RR, Kang K, Fishwick PA, editors. Proceedings of the 2000 winter simulation conference. 2000.

[73] Ho C, Ireland TC. Mitigating forecast errors by lot-sizing rules in ERP-controlled manufacturing systems. Int J Prod Res 2012;50:3080-94. 